
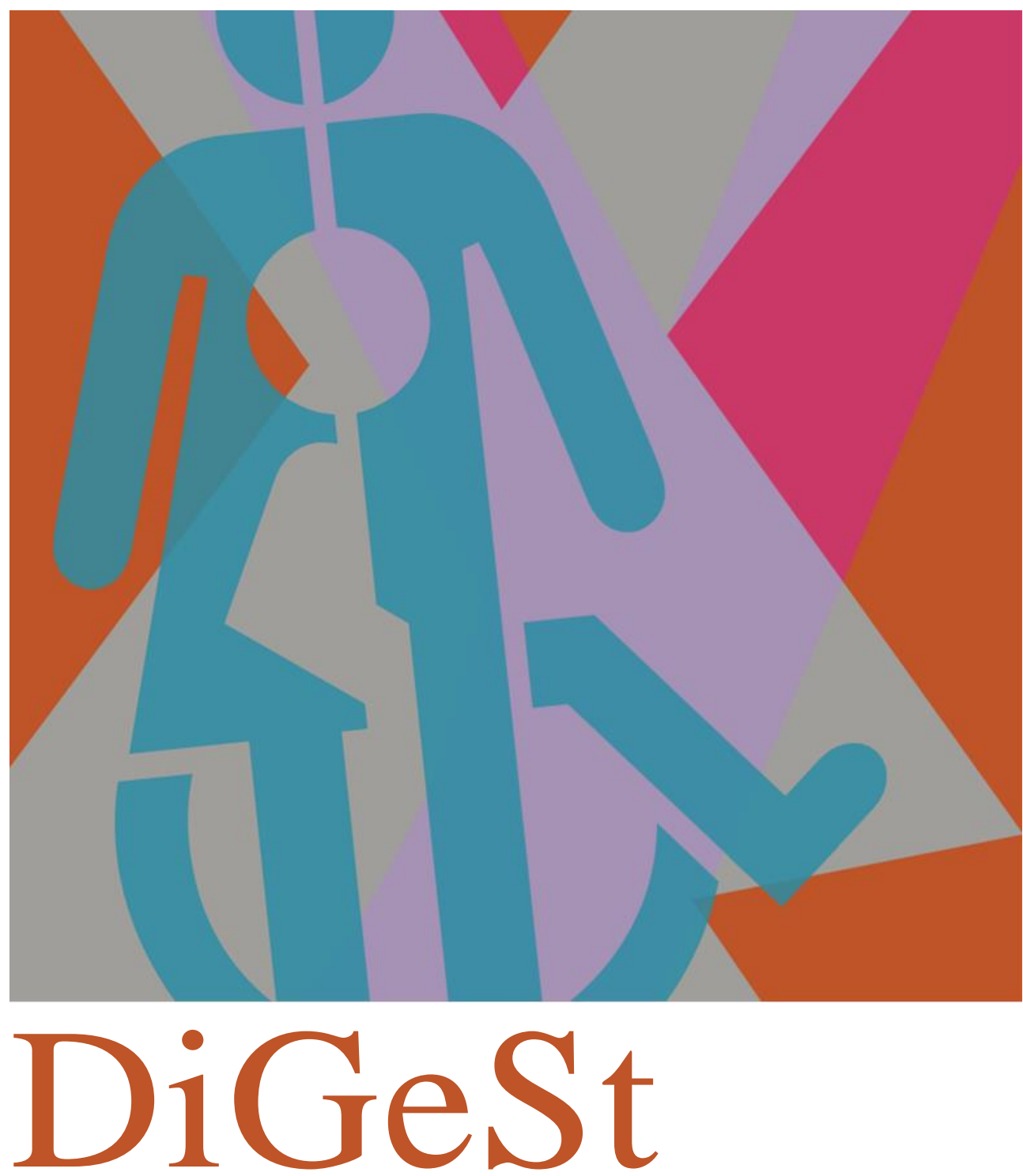

Journal of Diversity and Gender Studies

\title{
COVID-19 Roundtable
}

Luce Beeckmans, Anne-Marie D’Aoust, Valerie De Craene, Maria DiCenzo, Kristien Hens, Anneleen Kenis, Robert McRuer and AnneChristel Zeiter

DiGeSt Journal of Diversity and Gender Studies, Volume 8, Issue 1

Print ISSN: 2593-0273. Online ISSN: 2593-0281

Content is licensed under a Creative Commons BY

DiGeSt is hosted by Ghent University Website: https://ojs.ugent.be/digest 


\section{COVID-19 Roundtable}

The past year was an unprecedentedly challenging period to humanity. The very concept of a pandemic indicates a profound impact across different regions and societal strata, rendering the idea of unscathed human lives almost unimaginable. Still, this image of COVID-19 as a global threat menacing us all must not be allowed to efface the specificity of individual or communal struggles. This caveat is particularly relevant in the context of gender and diversity studies - the pertinence of which has been underscored countlessly over the past months, especially in policy recommendations to the COVID-19 pandemic. From the disproportionately severe measures aggravating isolation and destitution among the elderly to the coalescence of sanitary regulations and the BLM protests or the fire in the Moria refugee camp and the resulting urgency to address the wellbeing of displaced people: issues that relate intimately to notions of marginalization continually surface adjacent to the health crisis proper. Whether explicitly or implicitly, these circumstances call for gender and diversity scholars to commit their expertise to the benefit of those inordinately affected by COVID-19 and the array of responses it has evoked worldwide. At the same time, the conditions affecting these groups and individuals also affect research activities and advocacy work on gender and diversity, inhibiting the active commitment and scholarly involvement the situation demands. In this Spring 2021 General Issue, the Journal of Diversity and Gender Studies (DiGeSt) sought to explore the paradoxes, contradictions and tensions scholars in our field have faced and continue to face during the current COVID-19 crisis. Transcending a formally academic register, the roundtable includes personal, situated accounts that engage tensions between the pandemic and scholarly work in diversity and gender studies.

1

Luce Beeckmans - The politics of emotions of doing research on unprivileged housing and home-making while being locked down at home with my three little children

My research concerns the spatial dimensions of urban diversity. Currently, I am finalising an edited volume entitled 'Making Home(s) in Displacement: Critical Reflections on a Spatial Practice' together with Alessandra Gola, Ashika Singh and Hilde Heynen. Working on this book while being locked down at home has been confronting in many ways. First, because Covid-19 and subsequent measures, particularly stay-at-home-orders, have hit vulnerable groups (like refugees, homelessness people, people living in small, substandard or over-crowded housing) most severely, thereby strengthening existing inequalities. In response to these observations, I wrote a number of (opinion) pieces, among which a chapter with Stijn Oosterlynck entitled 'Lessons from the lockdown: foregrounding non-privileged perspectives into the (post-)covid city debate' (In Global Reflections on COVID-19 Urban Inequalities; published in Dutch as a column in De Standaard). Second, because reflecting on the diversity of spatial needs and the varying degrees of spatial poverty during the pandemic, made me realise more than ever how privileged I am, belonging to the 'white' middleclass, receiving a full salary at the end of each month to pay the mortgage.

In the past months, however, I have also struggled immensely with my own position as a female academic with three little children in a highly competitive research landscape. There is a degree of emotional contradiction involved here. Somehow, my personal feelings of loss, alienation and despair were strengthened by my deep acknowledgement of my privileged position. Yet, being locked down at home with my children (and partner) and caring for my sick 
mother, while at the same time and place having to perform a fulltime job, involving online teaching, coordinating research projects and participating in (online) international conferences, has been among the most challenging experiences I have gone through - regardless of our house, garden and generally high quality of life. I have tried to transform these feelings of hopelessness into positive activism. Together with Valerie De Craene and Anneleen Kenis, I co-authored a piece on the gender-based inequalities caused by Covid in academia (published in SamPol), which had an afterlife in an action of the 'Young Academy'. I also contributed to 'A slow science manifesto for a new praxis in higher education in post-corona times'. This text not only highlights how Covid (-measures) impact academics disparately, but also other groups indispensable to the functioning of universities, such as cleaning staff or cafeteria personnel.

Sometimes, these efforts to highlight unprivileged perspectives in pandemic times feel like a dangerous coping strategy, as they further consume my remaining energy, and merely add to an already significant workload. Some people question why I invest so much time in this, while, paradoxically, my message seems that the pandemic is capitalizing on the scarce space, time and energy people have left. But these contributions are also self-therapeutic and form my own way to negotiate this global pandemic. Other people don't understand why I don't simply quit working - perhaps some of them perceive my writings as instances of 'self-pity'. Reality is much more complex and nuanced. Measures like 'corona parental leave' are applicable to me too, but by embracing them I would disappoint my $(\mathrm{PhD})$ students, already suffering strongly from the situation. I would also endanger my own career perspectives and ambitions, as I am primarily on a short-time postdoctoral fellowship. Hence, I cannot but apply for other funding or positions, and these deadlines are not only inflexible but do not recognize Covid's impact in academia either. And why should I not be ambitious, when many of my colleagues unburdened by care and reproductive labour, can (perhaps even more than before Covid)?

Aside from analytic contributions on how undifferentiated Covid-measures exacerbate the situation for the urban unprivileged, I wrote one text voicing my own sudden unprivileged situation as a privileged person. It felt uncomfortable, as I was worried to be accused of posing. Yet, my intention was to explicate a broader societal problem many parents face during covid, but which is seemingly taken for granted. Indeed, there is some irony in measures that require precisely people able to work from home to keep their kids at home during pandemic peaks. It somehow felt as a disgrace, and I have wondered long to which aspect of myself exactly: my professional duties which are supposed to be executed in the company of a 1,4 and 6-year old or my mothering which I apparently should be able to fulfil with only a half eye? Or perhaps I felt embarrassed because it discredits the (pre-)school teachers whose work is seemingly no more than pointless day-care - as I am expected to execute their job while also working. By sketching my experiences, I aimed to give policymakers and employers (perhaps my own?) a candid view on how Covid was unevenly hampering careers and lives alike, bringing many parents in a permanent state of shortcoming towards work, children, meaningful others and themselves. But I also wanted to say to fellow parents (mothers in particular) that it is acceptable to talk about their struggles and challenges - certainly in the beginning of the covid-crisis, when we seemed somewhat blinded by a desire to beat the pandemic, while not sufficiently addressing the collateral damage of some measures for some groups.

Researching unprivileged housing and home-making while being locked down at home with my three children has not only been confronting. In certain ways, it has also been impossible. First, because the children's noise throughout the house limited my concentration span considerably. Even when they were silent, my awareness of their presence distracted me from doing my work, which was only intensified by feelings of guilt when letting them watch television for hours - even though they certainly did not complain. Since my children were allowed to return to day-care and school - although regularly interrupted by shorter lockdowns and preventive 
quarantines - my abilities to work have improved, but the pressure of the work that has piled up in combination with exhaustion, continue to affect my (working) condition. Secondly, researching unprivileged housing and home-making is also difficult in pandemic times, not in the least because conducting fieldwork has become almost impossible. Engaging instead in metareflection, including about my own positionality as a privileged scholar in a (temporarily) unprivileged situation, has somehow freed me from my alienation from fieldwork and frustrations about what I perceive as double (or triple?) failing. Speaking and participating in (online) public debates, has released me from the feeling to be pushed back in the home (execute reproductive and care labour solely) by a destructive neo-liberal (academic) system that continuously reproduces gender inequalities). It has been my way to fight back and re-channel my anxieties about my own situation and above all the world's current condition.

I am convinced that further (self-)reflection on unprivileged positions and spatialities is important if we want to mobilize this pandemic as a chance to come to more just and healthy cities and societies. As we have now all gone to some form of confinement, it is my deepest hope that the world will act with more empathy, understanding and above all vigour towards those whose existential position is bare (confinement) life. After all, chances are high that by next year I will be relieved from my temporary deprivation while the real unprivileged will still be locked down in their inequality.

Luce Beeckmans is Assistant Professor in Architecture and Urbanism related to Migration and Diversity at Ghent University (Department of Architecture and Urban Planning) and senior postdoctoral research fellow funded by the Flanders Research Foundation (FWO).

2

Anne-Marie D'Aoust - From the side of privilege: Caring inside the neoliberal university

Long before the pandemic, it was widely acknowledged that academia was not a caring, welcoming place - for women, for people of color, for LGBTQI+ people, for parents, for people outside the upper class. The gruesome "publish or perish!" mantra, the oft-unhealthy power dynamics between Ph.D. students and their advisers, the structural inequality between tenured professors and ever-precarious adjuncts living below the poverty line... The list goes on. The university nurtures certain attributes, certain qualities, certain skills, but certainly not people.

The pandemic did not bring this about. The neoliberal university, with its concern with performance, with the "students'/clients' experience", with productivity measured in research outputs, amounts of grant money and profit, was already being criticized and lamented for the inequalities it fed on and contributed in perpetuating. The pandemic not only accentuated them: it also revealed plainly that academia offers the same protection racket deal states do. This protection is not benevolent; it is offered at the cost of violence. Violence enacted upon others, as the examples above perfectly make clear, but also on you, the lucky ones who made it inside the system.

All around me, friends and colleagues say they should not complain. True, some colleagues unabashedly relish their comfortable status as full-time, tenured professors, with no dependents to care for, and no fear of losing income. Still, many others seem paralyzed with survivor's guilt. Repeating constantly that they.should.not.complain - sometimes despite depression and exhaustion, sometimes while caring for ill family members, sometimes while 
being sick themselves. Despite struggling and suffering, like so many others. Despite losing loved ones, and even colleagues, in a time when mourning is mostly experienced alone.

They are a strange thing to witness, these habitual zoom conversations punctuated with sentences that seemingly spill directly from the heart, uttered almost involuntarily, and cut short mid-flow with the inevitable "I'm sorry, I know I shouldn't complain. At least I'm not..." - insert here whatever your reference point is: an overworked health worker, a single working mother, an adjunct living below the poverty line, a relative who died alone of COVID.

Fully aware that "It does not get better than this" in academia, despite any challenge and suffering we might experience, my colleagues and I do not complain. People inside academia who usually do care work, service work, emotional work (mostly women and people of color), are exhausted, yet they apparently should not and do not complain. As if only a threshold of legitimate suffering - from whose perspective, exactly, remains unclear - had to be made to simply make the case of being fully human.

Too often, struggles to meet unattainable university expectations only get translated, heard or framed as "complaining". Yet, the pandemic revealed how the neoliberal university aims to subside at any cost, including our mental and physical health. I lost count of the times I repeated to colleagues that we were in a pandemic: it was normal to be unable to get back to our "normal" über-productive selves with research, teaching, writing, article reviews, grants writing and active supervision... But guilty feelings of not meeting expectations, accompanied by the shame of being perceived as complaining, keep creeping up. As if our worth continues to be defined by our ability to stay resilient (namely: productive) throughout the pandemic.

How come it has become almost impossible to simply utter feelings of despair, alienation or tiredness during a pandemic, to the point of feeling guilty to even think about it? Even if we "made it" inside the system, could we still not be critical about a university system that demands the same of us, and more, during a worldwide pandemic? A system that requires us to work as though the pandemic is not taking place, to make any transition, even those from classroom-tobedroom, look easy, seamless, and effortless - to enact the atomistic, independent researcher round the clock, trying to shut up our interconnected lives that might interfere with this fiction?

Since the start of the pandemic, discourses of care coming from university administrators have come at a regular pace: "Take care of yourself! Stay safe!" - vacuous formulas that obfuscate the embodiment, relationality, and materiality of care. Such messages came packaged with unabashed calls for resilience without further support, material, financial of otherwise. You ought to finish teaching online (even if your children are at home, even if family members are sick)! Or, conversely: You ought to be physically present for your classes (even if we don't have the means/will to ensure a safe working environment for you and your students)! But please, take care and stay safe. What does that even mean?

It strikes me that inside academia, most cannot conceive of care apart from a losing game. In academia, caring is suspect. It is dangerous for the current hierarchies of power in place. Ask any student or professors: we are usually struck by acts of kindness, either towards us or towards our work. We remember quite vividly who made the difference by being noticeably kind and helpful. In some odd, masochistic conception of academia, being able to "tough it up", to harden ourselves up (gendered undertone intended) and make harsh criticism gets conflated with "being professional." The same way studying the powerful is often seen has being professional as well - at least in my field of study.

But it should not be like this. Such a mindset precludes solidarities that extend beyond ourselves, conceived as unitary, self-made workers in distinct classes (the students, the professors, the adjuncts, etc.), not persons embedded in communities and family relations. It precludes the formation of solidarities, it precludes empathy. The stakes in caring (for each other, for others) are high. And they are political, in academia, as they are elsewhere. 
During a departmental meeting in fall 2020, we discussed whether we could help our colleagues who happen to be parents. A colleague quickly unfolded the slippery slope argument of caring. Are we not all suffering? If we start accommodating parent/professors, for instance, don't you think adjuncts will ask for something too, as they are often parents as well? If we start caring for each other, and then about the others, who are not like "us", where would this take us? And this is exactly what is at stake. It would take us to a point where we would collectively recognize the violence done to us and to others in the current power arrangements that structure the neoliberal university. Surely, we can do better than "not complain" and simply "be grateful to not be on the other side."

Anne-Marie D’Aoust works at the department of Political Science at the Université du Québec à Montréal (Canada). Her research seeks to theoretically and empirically explore the connections between love, security, governmentality and neoliberal practices.

3

\section{Valerie De Craene - Sitting on a bench}

I find myself sitting on a bench, roughly halfway the spring of 2020, overlooking an urban nature reserve in Ghent. It is only my second time outside my apartment since I got Covid-19 about forty days earlier, of which I spent thirty-five days in isolation. The astonishing view, the fresh air and a mild breeze, while enjoying the sun on my face, make me forget about the pandemic, if only for a couple of seconds. My scarf warms up the cool air before it enters my lungs, preventing shortness of breath. A meter and a half away from me, on the other side of the bench, sits my friend, who is about seven months - and therefore quite visibly - pregnant. In between us is a sign that says “keep on walking - corona doesn't take a break either". My friend is allowed to sit on this bench, and so are elderly people and young children; I risk a $250 €$ fine. She is not the one needing the break though, but I am relieved I can use her pregnancy as an excuse to give my body, especially my messed-up lungs that punish me for doing the slightest effort, some rest.

It is not the first time I experience the consequences of overlooking ill people's perspective during this pandemic firsthand. During those thirty-five days of illness and isolation, the only information available for those with symptoms was to stay inside, not contaminate other people, and not go to see a doctor, unless there was a 'real emergency'. With breathing becoming increasingly difficult every day, while simultaneously being devoid of any relevant medical information on my prognosis or even on what counts as a 'real emergency', finishing my $\mathrm{PhD}$ thesis provided me with a welcome distraction from doom scenarios of intubation and intensive care - an all too familiar image entering my home via television and social media. It's not that there existed no medical information on Covid-19 at the time, but it just did not seem the primary focus. Attention went exclusively to stopping the spread of the disease. Furthermore, the knowledge which was available often wasn't recognized as such. Compared to their European colleagues, Chinese health care workers had three months of additional experience in treating Covid-19 patients on a large scale, but their insights didn't make it into mainstream healthcare information. It was only when Italian doctors came to similar conclusions, patients like me received relevant information on how to relieve symptoms, or what to look out for when things worsened. It shows that what counts as knowledge, and who is considered a knowledge producer, is not neutral at all. Would we have reacted similarly if not Wuhan, but Washington or Wellington, were the first cities to go into complete lockdown? The organization of science is 
predicated on power dynamics, which are often overlooked, leading to epistemic injustice in which some perspectives are deemed more relevant than others. I had experienced epistemic injustice before, as scholars like me who work on sexualities, are also pushed to the margins of what counts as relevant academic knowledge. But now my own ill body experienced a whole new - much more material - dimension of unequal power relations in academic knowledge.

Illness and academia do not go well together. Contracts are rarely extended after taking sick leave, and when we return to work, we are often expected to 'simply' compensate the delay. Even then, we risk having to justify the 'gap in our cv' and 'lack of research output', hoping that this will help to avoid being labeled as an unproductive academic. The problem is that we keep imagining academics as being fit, healthy, fed, and rested all the time. Bodies that are ill, skinny, aging, pregnant, changing, tired, depressed, impaired, fat, stressed, etc., are considered or made to feel out of place. This is why I resolved to finish my $\mathrm{PhD}$, only allowing myself four days to recuperate, despite breathing problems. Afterwards, I continued working, started a new postdoc, and worked evenings and weekends on unpaid academic and activist activities - many of them to denounce exactly these structural inequalities exacerbated by Covid-19. I worked until July, but then my body stopped me. Immunity problems as a result of Covid-19 caused me to quit working for months. However, I didn't quit working completely. For almost each commitment I had made in healthier times, I was individually made responsible to find a solution. It turned out, for example, that defending my PhD was easier than postponing my defense, so I defended my dissertation while being sick. Another example is that I worked two full days to arrange an alternative session organizer at a conference which I couldn't convene anymore. I was reminded regularly how much stress my illness caused for the people I worked with. Indeed, finding a balance between self-disciplining or resisting the frame of the 'always on academic' in the publish or perish rat race did not affect me alone. Even though it's arguably easier for those in permanent contracts and positions of power, all academics face the pressure and stress that comes with universities' or funding agencies' obsession with 'accountability' through measurement, efficiency, and excellence, which considers all human embodied and emotional aspects to be manifestations of unproductivity. Many academics have internalized these toxic ideas. After a long period of being ill, I experienced a general lack of understanding of what being ill actually meant for me, even in the context of a pandemic. My postdoc contract ended up being shortened with almost a year due to my three months absence. This left me feeling I had no choice but to change jobs altogether. During the limited hours in which I was physically able to work and apply for scholarships, I found myself competing for funding with scholars who used the same "career breaks' box as I did by mentioning that they weren't able to complete their field work due to Covid-19 restrictions, while using the additional time to publish an unfinished book or paper (and why wouldn't they).

Not only Belgian policy makers ignore the perspective of ill people during this health pandemic. Academia doesn't have any structures to sit on a (metaphorical) bench when needed either.

Valerie De Craene currently enjoys her paid job as a researcher for the NGO Motief. She is also affiliated to Cosmopolis, VUB. She believes that these two sentence-bio's often suggest a very linear career path, while they obscure the messiness and precarity of short term academic contracts that many academics are confronted with. 
4

\section{Maria DiCenzo - Daughters of the Pandemic}

The emphasis in journalistic coverage of the pandemic's impact on women has focused primarily on their roles as mothers. With schools, daycares, and extended family care networks in shutdown, the pressures on working women have been overwhelming. But women are also daughters of elderly parents whose needs were already high and made more complex in the crisis. Atul Gawande, in his profound study of what matters at the end of life, Being Mortal (2014), notes that "your chances of avoiding the nursing home are directly related to the number of children you have, and ... having at least one daughter seems to be crucial to the amount of help you will receive." Without disparaging the efforts of many devoted sons, the reality is, like all 'care' sectors, women assume, disproportionately, the responsibility for the aged, regardless of the demands on them as professionals. While my point of departure is women as daughters, I will refer to 'caregivers' more generally.

I write as a senior academic (on the cusp of early retirement) who has in recent years been involved in assisting and caring for my elderly mother who passed away in September 2020 from non-Covid complications. She went from a protracted hospitalization, to convalescent care, to long-term care in a 5-month period, each stage more devastating physically and emotionally than the last. In the greater scheme of things, we were the lucky ones - she did not suffer cognitive decline and our family could draw on our own resources and the services and support available in the Canadian health care system. But the lessons learned have been difficult ones. Instead of writing about my personal experience, I would like to write from my experience to foreground the demands of elder care in the hope of raising awareness of how this affects professional commitments and how our skills as professionals serve us in the process. Your level of education can often make you the obvious choice for dealing with the bureaucracy of the health care system. At the same time, the structure of our teaching hours makes us seemingly more available and the invisibility (or less tangible nature) of our research makes it easier to overlook the need for time alone to concentrate, think, and write. Working from home looks like 'not working' to anyone unfamiliar with academic life.

There is a tendency to equate the elderly with children, but their physical, social, and emotional needs are very different - and complicated further by everything from cognitive function, hearing/vision loss, and mobility/disability, to cultural norms and expectations, linguistic barriers, and even technological/communicational ableism. Things were difficult enough pre-Covid-19. Many are often unaware of the administrative load and troubleshooting required on a regular basis - everything from assessment meetings with case workers, occupational therapists, managing drugs and physiotherapy, communicating with physicians, organizing diagnostic procedures, the preparation for and recovery from surgeries, etc. These exist in addition to personal care and domestic tasks such as food, laundry, cleaning. Even when sons are actively involved, there are things most elderly women only feel comfortable letting their daughters or other women to do. The moments of joy arise and must be cherished, but they become fewer and farther between. At the same time, one is increasingly conscious of the limited time remaining - when you weigh the relative importance of professional commitments and caring for a parent at the end of life it seems easy to think that the work can wait, especially if your career is not hanging in the balance.

The pandemic has complicated what was already a demanding, unpredictable, and logistically difficult caregiving situation. Negotiating the health care and social service system is a challenge at the best of times; seniors are not always reliable about the information they give (even when cognitively sound) because they are often motivated to protect their independence rather than their health. Generational and cultural factors can make them fearful of hospitalization 
and intimidated by medical professionals, so caregivers are crucial to offering context and narratives to make sense of episodes. As academics we are adept at documenting, managing diverse pieces of information, and offering concise narratives in articulate terms. We become indispensable.

If meeting the needs of the elderly felt like a losing battle before, the pandemic made it worse by changing the conditions of and opportunities for caregiving on several levels, both for seniors in their own homes and in institutions (note that over eighty percent of Covid-related deaths have been associated with long-term care homes in Canada). Lockdowns created a wall between the elderly and their families. We often think of caregiving in terms of the amount of work it entails. Working mothers who do most of the homeschooling and domestic work in addition to their jobs are overwhelmed by the sheer quantity of work. In the case of seniors in care homes, the pandemic created barriers to being able to provide care because family members were denied access. It has meant doing less and worrying more which generates feelings of guilt and failure. Ironically, the stress and anxiety grow in inverse proportion to the actual amount of work, as you wait for news of an outbreak or a new crisis to manage from a distance. It would be easier to be able to do that work, than knowing what happens when you can't, even if that work presents its own risks (I am middle-aged with an older partner, so we are at higher risk of illness). By taking away the ability to help in their physical care and to offer emotional support in normal and expected ways, the pandemic has created more stress and uncertainty for everyone involved, in spite of the heroic efforts of professional care workers.

Even for seniors living independently, the pandemic restrictions mean that the very people they need most become a danger; their needs do not diminish, nor can the system fulfill them adequately - the needs do not get met. The process of decline is unbearable under any circumstances but made worse by isolation. Some gerontologists have claimed that the benefits of safety measures have not been worth the suffering they cause, not to mention that the measures have failed miserably in many cases and the second wave has been deadlier than the first. For those suffering with dementia, unable to understand the situation, the experience is one of neglect and abandonment. It literally kills them. Ableism and ageism have contributed to marginalizing and diminishing the emotional and social needs of the elderly in the interests of physical safety and just keeping them alive. Perhaps the only good to come of this has been the heightened attention to the 'ethics of care' and the degree to which the pandemic has exposed the inadequacies of current systems and practices ("If the pandemic taught us anything"). As academics we can bring our experience on the personal front lines to bear on how we consider our needs within a work environment and how we might inform public discourse about the private sphere.

Maria DiCenzo is professor at the Department of English and Film Studies at Wilfrid Laurier University in Waterloo (Canada). She teaches courses in early 20th-century British literature, drama and theatre, and first-wave feminist print media.

5

Kristien Hens - LongCOVID and the bioethicist

I remember arguing with a colleague in February 2020 who had posted an anxious message on Facebook about exponential curves. Surely this was exaggerated: this coronavirus, as we would quickly take to calling it, would surely be stopped at the borders. And anyway, even if you got 
sick it, was not so bad all things considered. 2020 was going to be amazing. My career had taken a flight, and my husband and I had booked a family trip to Japan - our sons being at that age when such trips become possible and sensible. In March, the world became a different place. Around the time of the lockdown in Belgium, $13^{\text {th }}$ of March, my two oldest sons started complaining about a sore throat. They all coughed a lot. A week later, I had terrible muscle pain. And another week later, my husband and I got a sore throat as well. We laughed it off: maybe it's COVID, two weeks of coughing and we shall be immune and free. This was very much in line with the first wave's official narrative: you were either very very sick to the point of choking (and then you go the hospital), or you have mild symptoms for two or three weeks and get up and dance. For my family members, this was indeed the case. But in the first week of April, I completely lost my sense of smell. My sister, an ENT doctor, said it could take a year to return. "How on earth can they know?", I thought, "the thing was only discovered five months ago". With my sense of smell, I also lost my mind; or so it seemed at least. Words that would typically come quickly, became stored in drawers that I could not easily access. If you have a rather cerebral job, as I do, this is not exactly convenient. As an academic philosopher, I write. A lot. I had to install a powerful grammar and spelling checker because I could not see my mistakes: sentences became scrambled, and words miraculously omitted. But there is more. The fatigue comes back with a vengeance at exactly the moment you allow yourself to think it is gone forever. It lingers as a constant pressure on the chest. I had an antibody test in June and was prescribed two additional weeks of leave. By September, I became anxious and afraid these symptoms would become chronic and am at the time of writing enrolled in a three-months rehabilitation programme for people who had COVID. I am improving. Sometimes we go for a walk, and there are moments that I can smell cows or trees. The pressure on my chest is gone. Most of the time, my mind is back.

I rarely talk about this experience with people I do not know well, and I have been reluctant to write about it. For one, I understand that for many people, things have been and will be worse. I am a bioethicist, which means that I think about ethical issues about medical technologies and practices. For a bioethicist like me, the current pandemic is a real-life test case of how principles can be applied in circumstances where there is much at stake. This means reflecting on practical issues like resource allocation, but also on conceptual issues concerning the scope and depth of, for example, solidarity, and the meaning of risk. At the same time, being a long-hauler makes me reflect on the impact of my own experiences on my reflections: to which extent are these experiences valuable input to my reflection, or, as some would say, do they merely cloud my analytic vision? During the summer of 2020, there was a call from colleagues to urge the government to take other risk factors into account besides the merely epidemiological ones. Measurements are exaggerated, so they said, we are taking away the future of young people to protect others from a disease that is not that harmful for the vast majority of people. I understood their plea but could not join it based on my experience. But maybe that was in itself unjust. Why would my experience be important? Is this overly self-centred reasoning? Does it compare to the plight of children who are denied an education? At the same time, I was worried about my own hesitation to incorporate my experiences. As a bioethicist, I advocate incorporating all experiences and oppose to ethical reflection that only takes the interests of the majority into account. In fact, I believe firmly that understanding and taking into account the experiences of all people, affected in different ways, will eventually lead to more complex, but better realities. It is the task of the bioethicist not to merely stick to abstract principles, but to broker between different lives, to act as a systematizer of values and experiences, in order to suggest a way forward that is meaningful for all. This inextricably also includes one's own experience.

There is another aspect in which being a long-hauler illustrated a clash between my gut reactions and my firm beliefs. One of the pillars of my research is reflecting on the meaning of 
biology for psychiatric phenomena. It is true that a, perhaps reductionist, vision on biology seems to be essential to make specific experiences perceived as real. In my research on autism, I understood that the conceptualization of autism as a genetic variation, a neurobiologically 'real' difference is often what helps people with the diagnosis. But at the same time, there is also the fact that people with chronic fatigue are not taken seriously, precisely because no 'biological' cause can be found. I have always found this strange. I think it is the experience of difference or suffering is what should count. Moreover, I think such experiences are part and parcel of biology, be it a more holistic view on biology. Why did I then find it so crucial that the COVID antibody test was positive? That my fatigue was not due to pressure at work? This realization made me more aware of the persistence of the importance of biology for disease perception, a persistence that we cannot merely wish away by advocating for a more systemic view on health and disease. Still, I consider precisely that as the core of what it is that makes my job worthwhile.

Kristien Hens is assistant professor at the University of Antwerp. She is a bio-ethicist and is specifically interested in questions related to (epi)genetics, concepts of biology, feminism, disability studies and neurodiversity (autism, ADHD). Her current project NeuroEpigenEthics is funded by an ERC Starting Grant.

6

\section{Anneleen Kenis - Yet another invisible threat: navigating the germs in the air}

“A tissue, a tissue, ... we all fall down” (Old English nursery rhyme)

It is a sunny Sunday afternoon somewhere midway March 2020. We are following a nature trail in the British countryside, just a train ride away from London. Slightly lost, I am puzzling out how to find the way home. The kids are tired, and I would like to get them in bed before nightfall. Unlike Belgium and a number of other countries, schools are still open here and restrictive measures, like a lockdown, seemingly remain out of question for the time being. With slight feelings of alienation, people talk about other countries' policies. That doesn't mean the situation feels 'normal', though. The kids' hands look like raw meat due to them being washed with detergent ten times a day. The classrooms are emptier every day. No wonder we could use some fresh air. To clear our heads, to escape the city's feverishness for a day.

We didn't meet living beings other than bugs and sheep before stumbling upon a lady enjoying the sun leaned on an old, ruined wall. I approach to ask her about the way back. She doesn't react. I get a bit closer, still making sure to stay at least fifteen feet from her. Startled, she edges away. Asking whether I could please take some steps back and order my kids not to get too close to her. Inquiring what we are doing here. Immediately, my accent reveals we are not from the region. For one of the first times since we moved to London, I feel incredibly out of place.

The past years, I have been occupied with studying 'invisible' threats. First of climate change, and later air pollution. I have been studying how inconspicuous things, like merely breathing too often or too intensively in the wrong places, puts people at risk, and have scrutinized how people mentally map these threats. ${ }^{1}$ This mental mapping allows them to chart a course

\footnotetext{
${ }^{1}$ Kenis A and Lievens M (2021) Politicizing air: on the political effects of spatial imagination. In: Landau F, Pohl L and Roskam N (eds) [Un]Grounding: Post-Foundational Geographies. London: Transcript.
} 
through bad air. But it also makes them preoccupied with places where they can and cannot 'breathe' - sometimes even verging on hypochondria. My work shows that 'the intuitive' sometimes corresponds to but does not always match 'the rational'. In their judgements, people inevitably follow 'indicators' of bad air. With the finalisation of the project in sight, yet another invisible threat arrived: that of germs residing in and around (other) people's bodies. Suddenly, with every cough, every sneeze, every breath, risk started floating through the air. Germs able to land on surfaces, get attached to hands, and nest in people's mouth, lungs, and blood. Little tiny 'beings' whose presence is revealed only when it is already too late. ${ }^{2}$

So I was certainly no stranger to struggling with invisible, difficult to target 'culprits': both my main academic and political preoccupations, climate change and air pollution, display an enormous degree of 'elusiveness'. What characterises air pollutants like $\mathrm{NO}_{2}$ and $\mathrm{PM}_{\mathrm{x}}$, is that they are difficult to pin down. Only with the help of maps and statistics, their threat can be visualised. But the current crisis differs in one crucial respect: the object 'emitting' the invisible threat. Where air pollutants are emitted by cars, factories and other 'machines', it is now the human body that is responsible for the multiplication and spread of the threat. In my study on air pollution, people were advised to stay at least 1,5 meters from the roadside. Now, people are warned to keep that distance from each other. While atmospheric scientists underscore that pollutants not always disperse easily - sometimes lingering in place even if 'the culprit' is already gone, we even have to similarly fear human beings' past presence now.

But there are limitations to the comparison too. When I address air pollution and climate change, I argue that part of the problem is our preoccupation with the chemical composition, the invisible substance, the socio-natural artefact of $\mathrm{NO}_{2}, \mathrm{PM}_{\mathrm{x}}, \mathrm{CO} 2$ and a whole array of other gasses and particles. Instead, I've claimed, we must point at the factories, the cars, ... that emit them, as this allows us to clearly identify and target a here and now. But in relation to the COVID-19 pandemic, I feel the need to express, or perhaps even scream, the exact opposite. Let's not look at the people who might (have) contaminate(d) you, let's stick to the germs please. Let's not identify a (potential) threat in each other, in every other. Let's not track each other's movements, not fixate on each other's hugs. Let's not see the other as a risk to our own sanity. Let's stick to the knowledge that 'the culprit', 'the perpetrator', 'the enemy' could be everywhere, and tell ourselves there isn't much to gain by pointing to particular people or a particular place. Because when we start pointing to someone in particular, what is intuitive may very quickly diverge from what is rational, and very soon prejudices prevail. It is not just the other, but the unknown other. It is the untraceable other, talking in a strange accent, living in overpopulated neighbourhoods, too closely to each other, or living with too many in one place. For those living in the countryside, it might be people coming from the city, for city-dwellers it might be people coming from overseas.

For my kids, it's the one with the dirty hands, the one with stains on their jumper, the one who doesn't comb their hair. And then they forget about it again, as only kids can do. They play, sing 'ring around the rosie'. ${ }^{3}$ They sneeze, start arguing about the germs that might have been catapulted in the air. They wash their hands, and dramatically fall down.

Anneleen Kenis is senior post-doctoral research fellow of the Research Foundation Flanders (FWO) and associated with the Department of Earth and Environmental Sciences (KU Leuven) and Centre of Sustainable Development (CDO) (UGent). She holds a PhD in Bio-Engineering

\footnotetext{
${ }^{2}$ I write 'beings' between quotation marks because even if germs multiply themselves, and mutate in a variety of ways, they are not considered being 'alive'.

${ }^{3}$ Ring Around the Rosie is an old English nursery rhyme referring to the Great Plague, its symptoms, supposed cures and fatal consequences.
} 
Sciences (Political Ecology), and master degrees in Psychology and Sustainable Development and Human Ecology.

7

\section{Robert McRuer - Disability Art on Lockdown}

When the global lockdown of 2020 commenced, I said to a good friend with Environmental Illness (EI), "Undoubtedly, you brought a range of cripistemological skills that many people lack to this moment of crisis." Cripistemology is a term coined by Merri Lisa Johnson that has been in circulation for a decade to conceptualize embodied, disabled, or crip, ways of knowing. I didn't want to minimize the challenges so many friends faced during the pandemic; indeed, innumerable disabled people were far more at risk from the disease than nondisabled people, and in most locations, were much more likely to die from it (in England, for example, where disabled people are estimated at $16 \%$ of the population, they accounted for $59 \%$ of the deaths in the first few months of the pandemic). I simply wanted to validate that avoiding contagion; creating nontoxic living spaces; being more comfortable with slowness, creativity, and time at home; were skills she had cripistemologically nurtured for many years. Most nondisabled people had to try to learn these skills quickly and were simultaneously required to let go of a patronizing romanticization ("isn't it great that you get to be at home all the time!").

My own lockdown brought many changes that I was in fact better able to navigate because of my participation in disability culture and queer/crip studies. I was entering a sabbatical to work diligently on a new project, building on my previous work on disability and a global austerity politics; the new project was to focus on both austerity and on what has come to be called disability justice, in Latin America. I came to Bogotá, where my boyfriend lives, for ten days in March, planning to start research that would ultimately take me to a range of locations in Latin America. Ten days turned into six months and one of the most intense lockdowns in my friendship circle. I spent those six months with just one unmasked person and waited as my flight back to the states was cancelled over and over again. The other research trips I had planned were also cancelled and I found myself drawing on precisely those cripistemological ways of thinking that I gestured towards with my friend to replan how I would pass sabbatical.

Disability scholar Ellen Samuels notes that crip time is writing time-slow writing time, but writing time nonetheless. Leah Lakshmi Piepzna-Samarasinha makes similar points in her groundbreaking book Care Work: Dreaming Disability Justice. At the same time, the massive anxiety of 2020 at times worked to keep in check the possibility that immense amounts of writing time would emerge from lockdown. I did, however, begin to pay attention to the myriad ways that disabled people were generating art on lockdown, a few of which I will mention here. "Disability Art on Lockdown" began for me in June with DanceNYC's session "Disability Justice as the Vanguard of Recovery Thinking." Participants included Christopher Unpezverde Núñez, a visually impaired dancer, queer, Costa Rican immigrant to NYC; Dustin Gibson, a Pittsburghbased artist and activist working at the intersections of disability, race, class; Alice Sheppard, perhaps the most important wheelchair dancer in the United States, and Simi Linton, author of My Body Politic and producer and subject of the disability documentary Invitation to Dance. Acknowledging the challenges of our moment, these disability artists nonetheless affirmed what I had said to my friend, that disabled knowledges are indeed generative for how we might imagine life, community, and justice otherwise. Much of the initial discussion focused on language: over the course of the session, there was a lot of debate about how disability art might represent a 
vanguard of sorts, although there was debate about that word, and also debate over the word "recovery," as opposed to rejuvenation, reinvention, or multiple other possibilities for moving forward beyond the crises of 2020. The session was also broadly attentive to the intersections of race, class, disability, and gender, speaking to the ways in which multiple groups had been harder hit through the pandemic, but also to the knowledges that grow out of those marginalized locations.

My title for this brief piece, though, has a double valence, gesturing towards the ways in which disability and art have been, increasingly, on lockdown, facing massive cuts from governments and austerity everywhere, even before the crises of 2020. Mainstream media slowly reported on how the COVID-19 pandemic was affecting artists, but the redoubled challenge for disabled artists was rarely remarked upon outside of disability circles. Still, the production of disability art on lockdown, I discovered through the long, slow months, was proceeding apace, and globally. My hope is that the alternative ways of perceiving that artists put forward might be useful for navigating a world beyond COVID-19, but that will only happen if disability art is adequately supported. Some of those generating work over the year included: SinsInvalid, a performance group centering the work of people of color and credited with coining the concept of "disability justice"; Teatro Ciego [theater of the blind] in Mexico City, offering weekly performances centering non-visual modes of perception; and Estela Lapponi, a São Paulo-based disabled artist. Lapponi's pandemic performance SelfishCamera: Born to Be On Live was borne out of the artist's perception of the need to reinvent her artistic work, she wrote to me, "on COVID19's time." Her gaze as a dancer and performer has turned quite a lot to how we experience ourselves and others within the frame of the screen, to the perspectives in space, and to the disconcerting, dizzy, and often ableist movement of the selfie camera, due to the portability of the cell phone. Attempting to reflect on selfies capturing bodies otherwise, capturing the beauty of disable bodies, Lapponi carried out some experiments at her home, which culminated in SELFISHcamera, a tender and sexy virtual collaboration with guitarist and musician Lirinha Morini. Lapponi, like the other artists I've mentioned here, offers provocative and necessary ways of navigating the world otherwise, but valuing disabled lives, art, and beauty in the process.

Robert McRuer is an American theorist who has contributed to fields in transnational queer and disability studies. McRuer is known as being one of the founding scholars involved in forming the field of queer disability studies, particularly for a theoretical outlook known as crip theory. He is currently professor of English at The George Washington University in Washington, DC.

8

Anne-Christel Zeiter - Does it really matter now?

It was Friday, March 13, 2020. I returned to my office with a few boxes, even though I did not have any classes or meetings. I gathered all of my research data, sorted out anything that was of value to my work, synced my Clouds, and headed home.

During lockdown, I was supposed to write a book on asylum seekers' social and language practices in their host society, but I could not do so. Initially, I worked from home, which not only made supervising students challenging and time-consuming. I also did it from an open space office shared with very young colleagues: my children. With three computers and a garden, our family experienced a luxurious lockdown, but one that made working fairly difficult. More importantly, however, the book simply crippled me. When fetching my data to continue 
work from home, I suddenly experienced how life can change overnight firsthand. I experienced what it means to flee from unpredictable - or unbelievable - events, and felt uncomfortable. My discomfort was minimal; I was safe, at home and with my family. However, for the first time in my life, perhaps, I could grasp a glimpse of the fear, the anxiety, the uncertainties that are all too familiar for the refugees I work with.

Faced with this observation, I experienced an incredible feeling of emptiness. For whom, for what, should I write this work? I felt this kind of research would no longer be of interest anyone. Once again, the world was sinking into more urgent, more directly tragic concerns than the reinforcement of social inequalities through language. I suddenly felt useless; as if my work was in vain.

This feeling, which I have not yet completely overcome since, raises essential questions about our research's relevance. Even in 'normal' circumstances, it can sometimes be difficult to attribute commitment and intervention to the researchers operating in a university framework and society which, beyond their inequalities and daily dysfunctions, are relatively comfortable. But now, we are challenged to ask what happens in times of crisis, when society and the university become completely unhinged.

One year later, the emotional shock and initial surprise are behind us. We have settled into new standards and rules, more often than not imposed top-down, without the possibility of opposing or discussing them. Governments decide on the modalities of daily life, social relations, and consumption habits for the common good and public health, regardless of any apparent inconsistencies, and often ignoring ethical issues that may arise. Increasingly, the Covid-19 health crisis resembles a totalitarian turn, and many of us wonder what doors it will open in this direction. Indeed, "Covid discourses" articulate a veritable procession of fears and precautions, which all present arguments to justify hasty reforms, new measures, new norms.

In all fields (epidemiology, economics, politics, sociology, etc.), networks of signifiers are being built and metamorphosed from one discourse to another, from one piece of information to another, at nauseating speed: linear media and social networks can hardly keep up with the proliferation of opinions, and every half-certainty is swiftly met with its opposite. In an attempt to give meaning to what is happening, we multiply significations through all possible media and accelerate, instead, the loss of meaning and understanding to a point that it is almost instantaneous. The oversaturation of information and the almost endless complexity of the crisis' implications (economic, ecological, political, health, social) seem to render blind obedience and individual responsibility the only valid options.

These dynamics transcend borders and multiply the discourse of experts, authority, and propaganda. How far will we go, what will we obey? Furthermore, what place will our life before, and more specifically our scientific concerns have, in what is shaping up to be an economic, social, and ecological crisis? It is, of course, not a question of giving up in front of adversity, but of reflecting on what really matters in our research practices. What is left when the world we are familiar with begins to fall apart, and how or why can we keep on committing to what matters to us?

At the beginning of January 2021, I attended a Zoom session with stakeholders in socioprofessionnal support for migrants in my area. I suddenly realized that emergencies are always the same and that social, economic, health, and political uncertainty only makes them more salient. And so, the question I had been pondering was suddenly answered. Just as people fleeing their country do their best to pursue their goals and adapt to circumstances, I must continue to write this book, which has been on standby for almost a year. But I have to do this taking into account the shock and loss of meaning caused by the "Covid crisis", and trying to understand something applicable to my research. As intellectuals, it is our duty to deploy all of our critical resources when times are tough, and they are. We must commit ourselves to safeguard what 
matters to us, whatever our respective ideologies. But we must, at the same time, continue working: concern for the future shall not take all the place; we have to live and act today, too.

Anne-Christel Zeiter works at the University of Lausanne in Switzerland in the department of French as a Foreign Language. She specializes in language acquisition in a homoglot context, with a focus on language socialization. After working on multilingual couples, she now works on students abroad and (forcibly) displaced people. 